\title{
Comparison of Efficacy Between Open and Close Reduction in Supracondylar Fracture of Humerus in Children using Flynn's Criteria
}

\author{
Allah Rakha, Rana Dawood Ahmad Khan, Aqeel Arshad, Zeeshan Ali Khan, Shahbaz Ahmad, Shahzad Mahmood
}

\begin{abstract}
Background: In children, of all the elbow fractures $85 \%$ these occur in the distal humerus, supracondylar fractures are 55 to $75 \%$. Reducing the fracture using closed technique with per-cutaneous wiring and pins is proposed by many surgeons for third fracture type. One of the excellent methods for the treatment of these type of fractures involving humerus bone in pediatric population is through internal fixation using $\mathrm{K}$ wire. Objective: To compare the efficacy between open and close reduction in supracondylar fracture of humerus in children using Flynn's criteria. Study Design: A Randomized controlled trial. Settings: Orthopedics ward, Faisalabad Medical University, Faisalabad. Duration: 6 Months from 28 March 2018, 27 September 2018. Methodology: After taking approval from institutional ethical committee, patients were enrolled and randomly allocated in two groups. Patients in group A underwent open reduction and patients in group B underwent close reduction. Fracture fragments were reduced under vision in open reduction and under image intensifier in closed reduction and fixed with Kirshner's wires in crossing pattern. Patients were followed for 16 weeks postoperatively to assess the efficacy by using Flynn's criteria as per operational definition. Results: In our study, mean age was calculated as $7.28+1.74$ in Open reduction group and $7.37 \pm 1.88$ years in Closed reduction group, $80 \%(n=52)$ in Open reduction group and $75.38 \%(n=49)$ in Closed reduction group were male while $20 \%(n=13)$ in Open reduction group and $24.62 \%(n=16)$ in Closed reduction group were females, comparison of efficacy between open and close reduction in supracondylar fracture of humerus in children using Flynn's criteria shows that $89.23 \%(n=58)$ in Open reduction group and $93.85 \%(n=61)$ in Closed reduction group were treated effectively, $p$ value was 0.344 showing insignificant difference. Conclusion: We concluded that the efficacy of open and close reduction in supracondylar fracture of humerus in children using Flynn's criteria is not significantly different, however, the open reduction may be adopted where the image intensifier is not available.
\end{abstract}

Keywords: Children, Supracondylar fracture of humerus, Open reduction, Close reduction, Efficacy, Flynn's criteria.

Corresponding Author

Submitted for Publication: 12-12-2019

Accepted for Publication: 16-01-2020

DR. ALLAH RAKHA, Senior Registrar of Orthopedics, DHQ Hospital, Faisalabad Pakistan

Contact / Email: +92 333-6533667, allahrakha580@gmail.com

Citation: Rakha A, Khan RDA, Arshad A, Khan ZA, Ahmad S, Mahmood S. Comparison of Efficacy Between Open and Close Reduction in

Supracondylar Fracture of Humerus In Children Using Flynn's Criteria. APMC 2020;14(1):32-6.

\section{INTRODUCTION}

Among the common fractures in pediatric age group, those involving supra-condylar humerus bone part, are the $2^{\text {nd }}$ most commonly presenting cases. Of all pediatric elbow fractures about $50-60 \%$ are Supracondylar fractures. These fractures occur among pediatric age $4-11$ years in $85 \%$ children. ${ }^{1}$ Male gender is affected more often. Mostly children present before the age of 12. These types of fracture can lead to significant morbidity, with many complications and its increasing prevalence is making a difficult case to treat in most of the occasions. $^{1}$

The management has always faced a challenge in the form of Displaced supracondylar humerus fractures. Various techniques used in the management include reduction of the fractured bones with plaster casting, traction through the skin or through the other bone, reduction with pinning along with $\mathrm{K}$ wiring. Numerous inconveniences complicating the management of these type of fractures like Volkmann's ischemic injury, nervous or vascular injuries, myositis ossificans and cubitus Varus deformity make these patients more complicated and difficult to manage. The objective of treatment in a displaced fracture is to accomplish and keep up a close anatomical reduction till the fracture gives indications of association. ${ }^{4}$

Reducing the bone with close technique along with pinning and fixation is the method utilized and favored mostly by many consultant surgeons. ${ }^{5}$ This method was first portrayed by Swenson and later promoted by Flynn et al. Compared to other pin configurations It is bio-mechanically more stable, simple with distinguished results. ${ }^{3}$ Reducing the bone with close technique along with pinning and fixation using K-wires is proposed by many surgeons for type III fractures under image intensifier.

Be that as it may in most hospitals in Pakistan, the reason why different practice's like side arm traction and open reduction internal fixation with wires are used to handle supracondylar fractures is due to non-availability of image intensifier. An excellent method for humeral fracture in pediatric population is by reducing the bone and fixing through $\mathrm{K}$ wire, when the fracture is open or when good reduction cannot be achieved by closed means. Utilitarian result can be poor with late introduction of patient and deferred treatment. ${ }^{6}$

Satisfactory outcome with closed reduction was $99.28 \%$ and unsatisfactory was $0.72 \% .^{3}$ Satisfactory outcome with open reduction was $88.89 \%$ and unsatisfactory was $11.11 \% .^{1}$ In another study, satisfactory outcome with open reduction was $97.47 \%$ and unsatisfactory was $2.5 \%{ }^{6}$ Satisfactory outcome with closed reduction $95.45 \%$ and unsatisfactory was $4.55 \%{ }^{7}$

Supracondylar fracture in children is one of the common problems presenting in tertiary care hospitals. As there is debate in literature with respect to the utilization of open reduction or closed reduction for the administration of supracondylar 
fractures in children. So, the results of my research will be useful in choosing an appropriate treatment methodology for the treatment for supracondylar fractures in children. The goal of this study was to utilize Flynn's criteria to analyze the adequacy between open and close reduction in supracondylar fracture of humerus in children.

\section{METHODOLOGY}

Study Design: Randomized clinical trial.

Settings: Department of Orthopedics, Allied Hospital, Faisalabad Pakistan.

Duration: 6 Months from 28 March 2018, 27 September 2018. Sample Technique: Non-probability consecutive sampling.

Sample Size: 130 cases (65 in each group)

Inclusion Criteria: All patient of either gender of age ranging from 5-12 years with supracondylar fracture of humerus (as per operational definition) in a period of one week of the fracture of Gartland type III (completely displaced with no cortical contact) diagnosed on X-ray were included in the study.

Exclusion Criteria: Any patient with open or closed Gartland type-III fracture associated with neurovascular injury, previous fracture in the same elbow or associated ipsilateral fractures were excluded from the study.

Methods: By utilizing the WHO sample size calculator, sample size was calculated for two proportions, $P_{1}=99.28 \% 3 \mathrm{P}_{2}=$ $88.89 \%{ }^{1}$ taking power of study of $80 \%$, and level of significance of $5 \%$. Supracondylar fracture of humerus was defined as any break in the continuity of bone of humerus just above the level of humeral condyles diagnosed by taking AP and lateral radiographs of the involved elbow. Efficacy was measured in terms of satisfactory and unsatisfactory results by using Flynn's criteria at $16^{\text {th }}$ week postoperatively. Flynn's criteria is as follows:

\begin{tabular}{|c|c|c|c|}
\hline Outcome & Rating & $\begin{array}{c}\text { Cosmetic } \\
\text { factor } \\
\text { (Carrying angle } \\
\text { loss in degrees) }\end{array}$ & $\begin{array}{c}\text { Functional } \\
\text { factor } \\
\text { (Movements } \\
\text { loss in degree) }\end{array}$ \\
\hline \multirow{3}{*}{ Satisfactory } & Excellent & $0-5$ & $0-5$ \\
\cline { 2 - 4 } & Good & $6-10$ & $6-10$ \\
\cline { 2 - 4 } & Fair & $11-15$ & $11-15$ \\
\hline Unsatisfactory & Poor & $>15$ & $>15$ \\
\hline
\end{tabular}

Null hypothesis of this study was 'using flynn's criteria there is no difference between open and close reduction in supracondylar fracture of humerus.' and alternate hypothesis of this study was 'using flynn's criteria there is some difference between open and close reduction in supracondylar fracture of humerus in children.

Approval from intuitional ethical committee was taken, patients coming through emergency satisfying the inclusion criteria were selected and informed assent was taken. Computer generated random number table was used to divide Patients in two equivalent groups.
Patients in group A were subjected to open reduction and patients in group $B$ were subjected to close reduction.

All patients were operated upon by consultant orthopedic surgeons under general anesthesia. Fracture fragments were reduced under vision in open reduction and under image intensifier in closed reduction and fixed with Kirshner's wires in crossing pattern. Patients were followed for 16 weeks postoperatively to assess the efficacy by using Flynn's criteria as per operational definition. Clinical assessment of range of elbow motion was measured by using a goniometer. Carrying angle was measured by AP and lateral radiographs which were taken in radiology department of hospital and it was reported by radiologist. Patient's contact information was taken for followup. I used a specially designed proforma (attached) to collect the information.

Data collected was analyzed using SPSS 20. Descriptive variables of quantitative nature will be expressed in terms of mean and standard deviation, variables are age and duration of fracture. For qualitative variable like gender, side of fracture and efficacy frequency and percentage was calculated. Chi-square test was applied to compare efficacy between two groups. Effect modifiers like age, gender, side of fracture and duration of fracture were controlled by stratification. Post stratification chisquare test was applied. P-value $\leq 0.05$ was considered significant.

\section{RESULTS}

Total 130 cases (65 in each group) satisfying the incorporation/prohibition criteria were selected to compare using Flynn's criteria the efficacy between open and close reduction in supracondylar fracture of humerus in children.

Age distribution shows that $93.85 \%(n=61)$ in Open reduction group and $92.31 \%(n=60)$ in Closed reduction group were between $5-10$ years of age whereas $6.15 \%(n=4)$ in Open reduction group and $7.69 \%(\mathrm{n}=5)$ in Closed reduction group were between $11-15$ years of age, Mean \pm SD was calculated as $7.28 \pm 1.74$ in Open reduction group and $7.37 \pm 1.88$ years in Closed reduction group. (Table 1)

Table No. 1: Age distribution $(n=130)$

\begin{tabular}{|c|c|c|c|c|}
\hline \multirow{2}{*}{$\begin{array}{c}\text { Age (in } \\
\text { years) }\end{array}$} & \multicolumn{2}{|c|}{$\begin{array}{c}\text { Open reduction } \\
\text { group ( }(\mathrm{n}=65)\end{array}$} & \multicolumn{2}{c|}{$\begin{array}{c}\text { Closed reduction } \\
\text { group ( } \mathrm{n}=65)\end{array}$} \\
\cline { 2 - 5 } & $\begin{array}{c}\text { No. of } \\
\text { patients }\end{array}$ & $\%$ & $\begin{array}{c}\text { No. of } \\
\text { patients }\end{array}$ & $\%$ \\
\hline $\mathbf{5 - 1 0}$ & 61 & 93.85 & 60 & 92.31 \\
\hline $11-12$ & 4 & 6.15 & 5 & 7.69 \\
\hline Total & 65 & 100 & 65 & 100 \\
\hline Mean $\underline{\mathbf{s}}$ & \multicolumn{2}{|c|}{$7.28 \pm 1.74$} & \multicolumn{2}{|c|}{$7.37 \pm 1.88$} \\
\hline
\end{tabular}

Gender distribution shows that $80 \%(n=52)$ in Open reduction group and $75.38 \%(n=49)$ in Closed reduction group were male while $20 \%(n=13)$ in Open reduction group and $24.62 \%(n=16)$ in Closed reduction group were females. (Table 2) 
Table 2: Gender distribution $(n=130)$

\begin{tabular}{|c|c|c|c|c|}
\hline \multirow{2}{*}{ Gender } & \multicolumn{2}{|c|}{$\begin{array}{c}\text { Open reduction group } \\
(\mathbf{n}=65)\end{array}$} & \multicolumn{2}{c|}{$\begin{array}{c}\text { Closed reduction group } \\
(\mathbf{n}=65)\end{array}$} \\
\cline { 2 - 5 } & No. of patients & $\%$ & No. of patients & $\%$ \\
\hline Male & 52 & 80 & 49 & 75.38 \\
\hline Female & 13 & 20 & 16 & 24.62 \\
\hline Total & 65 & 100 & 65 & 100 \\
\hline
\end{tabular}

Side of fracture shows that $53.85 \%(n=35)$ in Open reduction group and $41.54 \%(n=27)$ in Closed reduction group had fracture on right side whereas $46.15 \%(n=30)$ in Open reduction group and $58.46 \%(n=38)$ in Closed reduction group had left side. (Table 3 )

Table 3: Side of fracture $(n=130)$

\begin{tabular}{|c|c|c|c|c|}
\hline \multirow{2}{*}{ Side } & \multicolumn{2}{|c|}{$\begin{array}{c}\text { Open reduction group } \\
(\mathbf{n}=65)\end{array}$} & \multicolumn{2}{c|}{$\begin{array}{c}\text { Closed reduction } \\
\text { group }(\mathbf{n}=65)\end{array}$} \\
\cline { 2 - 5 } & $\begin{array}{c}\text { No. of } \\
\text { patients }\end{array}$ & $\%$ & $\begin{array}{c}\text { No. of } \\
\text { patients }\end{array}$ & $\%$ \\
\hline Right & 35 & 53.85 & 27 & 41.54 \\
\hline Left & 30 & 46.15 & 38 & 58.46 \\
\hline Total & 65 & 100 & 65 & 100 \\
\hline
\end{tabular}

Comparison of efficacy between open and close reduction in supracondylar fracture of humerus in children utilizing Flynn's criteria shows that $89.23 \%(n=58)$ in Open reduction group and $93.85 \%(n=61)$ in Closed reduction group were treated effectively while remaining $10.77 \%(n=7)$ in Open reduction group and $6.15 \%(n=4)$ in Closed reduction group were not treated effectively, $p$ value was 0.344 showing insignificant difference. (Table 4)

Table 4: Compare the efficacy between open and close reduction in supracondylar fracture of humerus in children using Flynn's criteria ( $n=130)$

\begin{tabular}{|c|c|c|c|c|}
\hline \multirow{2}{*}{ Efficacy } & \multicolumn{2}{|c|}{$\begin{array}{c}\text { Open reduction group } \\
(\mathbf{n}=65)\end{array}$} & \multicolumn{2}{c|}{$\begin{array}{c}\text { Closed reduction group } \\
(\mathbf{n}=65)\end{array}$} \\
\cline { 2 - 5 } & No. of patients & $\%$ & No. of patients & $\%$ \\
\hline Yes & 58 & 89.23 & 61 & 93.85 \\
\hline No & 7 & 10.77 & 4 & 6.15 \\
\hline Total & 65 & 100 & 65 & 100 \\
\hline
\end{tabular}

$P$ value $=0.344$

The data was stratified for age, gender, side of fracture and duration of fracture were controlled by stratification. Post stratification chi-square test was applied. P-value $\leq 0.05$ was considered significant. (Table No. 5-7)
Table 5: Stratification for with regards to age

\begin{tabular}{|c|c|c|c|}
\hline \multirow{2}{*}{ Group } & \multicolumn{2}{|c|}{ Efficacy } & $P$ value \\
\hline & Yes & No & \multirow{3}{*}{0.35} \\
\hline $\begin{array}{c}\text { Open } \\
\text { reduction }\end{array}$ & 54 & 7 & \\
\hline $\begin{array}{c}\text { Closed } \\
\text { reduction }\end{array}$ & 56 & 4 & \\
\hline
\end{tabular}

11-12 years
\begin{tabular}{|c|c|c|c|}
\hline \multirow{2}{*}{ Group } & \multicolumn{2}{|c|}{ Efficacy } & P value \\
\cline { 2 - 3 } & Yes & No & \multirow{2}{*}{$\begin{array}{c}\text { Cannot } \\
\text { compute }\end{array}$} \\
\hline $\begin{array}{c}\text { Open } \\
\text { reduction }\end{array}$ & 4 & 0 & \\
\hline $\begin{array}{c}\text { Closed } \\
\text { reduction }\end{array}$ & 5 & 0 & \\
\hline
\end{tabular}

Table 6: Stratification for with regards to gender

Male
\begin{tabular}{|c|c|c|c|}
\hline \multirow{2}{*}{ Group } & \multicolumn{2}{|c|}{ Efficacy } & \multirow{2}{*}{ P value } \\
\cline { 2 - 3 } & Yes & No & \\
\hline $\begin{array}{c}\text { Open } \\
\text { reduction }\end{array}$ & 48 & 4 & \multirow{2}{*}{0.44} \\
\hline $\begin{array}{c}\text { Closed } \\
\text { reduction }\end{array}$ & 47 & 2 & \\
\hline
\end{tabular}

Female

\begin{tabular}{|c|c|c|c|}
\hline \multirow{2}{*}{ Group } & \multicolumn{2}{|c|}{ Efficacy } & \multirow{2}{*}{ P value } \\
\cline { 2 - 3 } & Yes & No & \\
\hline $\begin{array}{c}\text { Open } \\
\text { reduction }\end{array}$ & 10 & 3 & \multirow{2}{*}{0.45} \\
\hline $\begin{array}{c}\text { Closed } \\
\text { reduction }\end{array}$ & 14 & 2 & \\
\hline
\end{tabular}

Table 7: Stratification for with regards to side of fracture

Right
\begin{tabular}{|c|c|c|c|}
\hline \multirow{2}{*}{ Group } & \multicolumn{2}{|c|}{ Efficacy } & \multirow{2}{*}{ P value } \\
\cline { 2 - 3 } & Yes & No & \multirow{2}{*}{0.04} \\
\hline Open reduction & 30 & 5 & \\
\hline Closed reduction & 27 & 0 & \\
\hline
\end{tabular}

\begin{tabular}{|c|c|c|c|}
\hline \multirow{2}{*}{ Group } & \multicolumn{2}{|c|}{ Efficacy } & $P$ value \\
\hline & Yes & No & \multirow{3}{*}{0.42} \\
\hline $\begin{array}{c}\text { Open } \\
\text { reduction }\end{array}$ & 28 & 2 & \\
\hline $\begin{array}{c}\text { Closed } \\
\text { reduction }\end{array}$ & 37 & 1 & \\
\hline
\end{tabular}




\section{DISCUSSION}

Of the upper limbs in children, the most common site for the occurrence of fractures exceeded only by forearm is the elbow. In children of all the elbow fractures, $85 \%$ occur in the distal humerus, supracondylar fractures are 55 to $75 \%$, accounting for $3 \%$ of all fractures. The causes include Direct or indirect lowkinetic energy traumas, for example falls, which makes the event of comminution, exposure of bone or association with other fractures less frequent. Closed reduction and percutaneous pinning with wires is proposed by many surgeons for type III fractures. In most hospitals in Pakistan, the reason why different practice's like sidearm traction along with openreduction and wire fixation are used to handle supracondylar fractures is due to non-availability of image intensifier. An excellent method for the treatment of such type of fractures in pediatric population is through open-reduction along with $\mathrm{K}$ wiring, specifically in cases with open fractures or in cases when adequate reduction cannot be achieved using by closed technique. Utilitarian result can be poor with late introduction of patient and deferred treatment. As there is debate in literature with respect to the utilization of open reduction or closed reduction in these types of fractures. So, the results of my research will be useful in choosing an appropriate treatment methodology for the treatment for supracondylar fractures in children.

In our study, mean age was calculated as $7.28+1.74$ in Open reduction group and $7.37 \pm 1.88$ years in Closed reduction group, $80 \%(n=52)$ in Open reduction group and $75.38 \%(n=49)$ in Closed reduction group were male while $20 \%(n=13)$ in Open reduction group and $24.62 \%(n=16)$ in Closed reduction group were females, comparison of efficacy between open and close reduction in supracondylar fracture of humerus in children using Flynn's criteria shows that $89.23 \%(n=58)$ in Open reduction group and $93.85 \%(n=61)$ in Closed reduction group were treated effectively, $p$ value was 0.344 showing insignificant difference.

Previous studies reveal that satisfactory outcome with closed reduction was noted to be $99.28 \%$ and unsatisfactory was $0.72 \% .{ }^{3}$ Satisfactory outcome with open reduction was $88.89 \%$ and unsatisfactory was $11.11 \% .^{1}$ In other study satisfactory outcome with open reduction was noted to be $97.47 \%$ and unsatisfactory was $2.5 \%{ }^{6}$ Satisfactory outcome with closed reduction $95.45 \%$ and unsatisfactory was $4.55 \%{ }^{7}$

The results of our study are in concurrence with the above investigations with slight distinction. Kanwar Lal and others ${ }^{8}$ analyzed and compared the improvement in the bone anatomy after cross pinning through the skin method in comparison with second method of management involving 2-outer-side pinning along with complications of both techniques. They recorded that carrying angle loss was present in $10 \%$ patients in first technique and in $20 \%$ patients of second method while about $15 \%$ of the cases had loss of motion in first technique group while $25 \%$ in second technique. They inferred that contrasted with lateral pinning, the administration with percutaneous cross pinning is better and more progressively method for treating such humeral fractures.
In accordance with our findings, we are of the view that when closed reduction is deficient then open reduction and internal fixation of supracondylar fractures ought to be designated. An adequate reduction using the closed technique may not be possible for displaced fractures of type-III having no cortical contact along with disturbed periosteal lining, and in cases with compound fractures involving the skin; if after attempts at closed reduction with the child under general anesthesia, bony remnants cannot be correctly placed, and are held with pinning through the skin, reduction of the bone ends using open technique with fixation are indicated.

Likewise, cases with seriously swollen that a closed reduction can't be kept up, at that point olecranon traction may be utilized for a few days. Other indications for O.R.I.F. incorporate open (compound) fractures that require irrigation and debridement and those fractures complicated by vascular injury, myositis ossificans excessive callus formation with residual stiffness, and decreased range of motion.

If first described technique was used, they ought to be performed after the swelling has diminished, however no later than 5 days after that time in light of the fact that the likelihood of myositis ossificans increments after that time.

31 difficult Fractures were treated by Gruber and Hudson with open reduction and internal fixation and observed Satisfactory outcomes even in the most serious ones.

The findings of our study revealed that supracondylar fractures might be supervised by different techniques like open reduction internal fixation with wires and side arm traction where image intensifier is not available.

\section{CONCLUSION}

We concluded that the efficacy open and close reduction in supracondylar fracture of humerus in children using Flynn's criteria is not significantly different, however, the open reduction may be adopted where the image intensifier is not available.

\section{LIMITATIONS}

Some of my patients who initially contributed in study were lost in follow-up.

\section{SUGGESTIONS / RECOMMENDATIONS}

Further research is required to increase credibility of comparison.

\section{CONFLICT OF INTEREST / DISCLOSURE}

There is no conflict of interest involved.

\section{ACKNOWLEDGEMENTS}

I would like to pay my thanks to my colleagues who helped me lot in conducting of my research.

\section{REFERENCES}

1. Aslan A, Konya MN, Ozdemir A, Yorgancigil H, Maraclan G Uysal $E$. Open reduction and pinning for the treatment of Gartland extension type III supracondylar humeral fractures in children. Strategies Trauma Limb Reconstr. 2014;9(2):79-88. 
2. Sarrafan N, Nasab SA, Ghalami T. Treatment of displaced supracondylar fracture of the humerus in children by open pining from lateral approach: an investigation of clinical and radiographical results. Pak J Med Sci. 2015;31(4):930-5.

3. Bhuyan BK. Close reduction and percutaneous pinning in displaced supracondylar humerus fractures in children. J Clin Orthop Trauma. 2012;3(2):89-93.

4. Mohammed R, Bhogadi P, Metikala S. A study of biplanar crossed pin construct in the management of displaced pediatric supracondylar humeral fractures. J Child Orthop. 2014;8(5):43541.

5. Sahu RL. Percutaneous K-wire fixation in paediatric Supracondylar fractures of humerus: a retrospective study. Niger Med J. 2013;54(5):329-34.
6. Ahmad Khan RD, Yousaf MN, Zain-Ur-Rehman M, Fareed MI, Yasin A. Outcome of open reduction internal fixation with cross K-wires for supracondylar fracture of humerus in terms of Flynn's criteria in children. J Pak Med Assoc. 2015;65(3):186-9.

7. Turgut $\mathrm{A}$, Kalanderer $\mathrm{O}$, Bozoglan $\mathrm{M}$, Bacaksiz $\mathrm{T}$, Agus $\mathrm{H}$. Flexion type supracondylar humerus fractures: 12-year experience of a pediatric orthopedics clinic. Eklem Hastalık Cerrahisi. 2015;26(3):151-7.

8. Lal K, Laghari MA, Bhutto IA, Kumar K. Supracondylar Fracture of Humerus in Children Treated with closed Reduction and Percutaneous Cross Pinning vs two Lateral Pinning. JLUMHS 2014;13(2):71-5.

\section{AUTHORSHIP AND CONTRIBUTION DECLARATION}

\begin{tabular}{|c|c|c|}
\hline AUTHORS & Contribution to The Paper & Signatures \\
\hline $\begin{array}{l}\text { Dr. Allah Rakha } \\
\text { Senior Registrar of Orthopedics } \\
\text { DHQ Hospital, Faisalabad Pakistan }\end{array}$ & Data Collection & \\
\hline $\begin{array}{l}\text { Dr. Rana Dawood Ahmad Khan } \\
\text { Associate Professor of Orthopedics } \\
\text { FMU / DHQ Hospital, Faisalabad Pakistan }\end{array}$ & Data Collection & \\
\hline $\begin{array}{l}\text { Dr. Aqeel Arshad } \\
\text { Medical Officer of Orthopedics } \\
\text { DHQ Hospital, Faisalabad Pakistan }\end{array}$ & Reading \& Assessment & \\
\hline $\begin{array}{l}\text { Dr. Zeeshan Ali Khan } \\
\text { Assistant Professor of Orthopedics } \\
\text { FMU / DHQ Hospital, Faisalabad Pakistan }\end{array}$ & Reading \& Assessment & \\
\hline $\begin{array}{l}\text { Dr. Shahbaz Ahmad } \\
\text { Medical Officer of Orthopedics } \\
\text { DHQ Hospital, Faisalabad Pakistan }\end{array}$ & Reading \& Assessment & 2 \\
\hline $\begin{array}{l}\text { Dr. Shahzad Mahmood } \\
\text { Senior Registrar of Orthopedics } \\
\text { DHQ Hospital, Faisalabad Pakistan }\end{array}$ & Reading \& Assessment & shat \\
\hline
\end{tabular}

